\title{
Práticas ecoturísticas no Parque Nacional de Sete Cidades (PI) na perspectiva do turismo sustentável
}

\section{Ecotourism practices in the "Sete Cidades" National Park (PI, Brazil) in the perspective of sustainable tourism}

\author{
Ricardo Gomes Ramos, Luísa Cristina Paiva e Paixão
}

\begin{abstract}
RESUMO
Diante do aumento da demanda pelo turismo em áreas naturais, motivado pela busca do contato do ser humano com áreas não urbanizadas como forma de refúgio dos problemas encontrados nos centros urbanizados, temse o Ecoturismo como uma das segmentações que proporciona a relação homem - natureza de forma contemplativa. O presente trabalho busca analisar, em conformidade aos princípios do turismo sustentável, de que forma a relação turista-atrativo vem sendo desempenhada no Parque Nacional de Sete Cidades (PN7C), localizado na porção meio-norte do estado do Piauí. Com base na observação da conduta desempenhada por turistas no processo de visitação a esse patrimônio natural, traçou-se um diagnóstico que possibilitou o apontamento de ações a se adotar, por parte dos administradores do parque, como forma de proporcionar práticas ecoturísticas colaborativas à conservação do meio visitado.
\end{abstract}

PALAVRAS-CHAVE: Parque Nacional de Sete Cidades; Ecoturismo; Turismo sustentável.

\section{ABSTRACT}

Due to increase in demand for tourism in natural areas, motivated by the needs of human being and its contact to non-urbanized areas as a way to scape from problems usually observed at urbanized centers, the ecotourism is one of the segmentation that provides the human being - environment relashionship into a contemplative way. This paper aims to analyse, according to sustainable tourism, how the relationship between tourists and tour spots is being performed at Sete Cidades National Park (PN7C), located at Piauí's state mid-north portion. Based on behavior performed by tourists during its visit on that natural heritage, a diagnosis was made allowing the apointment of actions to be adopted by the administration of this natural park, as a way to provide eco touristic practices whom may collaborate to environment conservation.

KEYWORS: Sete Cidades National Park; Ecotourism; Sustainable Tourism. 


\section{Introdução}

A relação entre o ser humano e a natureza nem sempre foi baseada na degradação e destruição já que, de acordo com registros históricos, há milhares de anos, a extração de insumos baseava-se em sua sobrevivência promovendo a caça e a pesca de forma sustentável, ou seja, apoderando-se apenas daquilo que utilizaria.

Com o passar dos anos esta relação começou a ser modificada, surgindo então o plantio dos alimentos e a domesticação dos animais para fins comerciais, ocasionando o desmatamento, queimadas, e caça predatória fazendo com que a relação com o meio natural, baseada no respeito e na sustentabilidade, fosse substituída por um cenário de destruição, pois, preocupando-se somente com seus interesses econômicos, esqueceu-se da importância das florestas, dos animais, dos rios, urbanizando a paisagem, criando para si um modelo de autodestruição (Beni, 2000).

Contemporaneamente, na tentativa de recuperar-se do caos observado nas grandes metrópoles, o homem procura ocupar parte ou até mesmo todo seu tempo livre, com atividades ligadas à natureza, e em sua grande maioria relacionadas ao turismo, como observa Ruschmann (2001, p.9):

O turismo contemporâneo é um grande consumidor da natureza e sua evolução, nas últimas décadas, ocorreu como consequência da "busca do verde" e da "fuga" dos tumultos dois grandes conglomerados urbanos pelas pessoas que tentam recuperar o equilíbrio psicofísico em contato com os ambientes naturais durante seu tempo de lazer.

De acordo com o exposto, deve-se destacar que, pelo fato de utilizar seu tempo livre em atividades relacionadas ao contato com a natureza estas, em sua grande maioria, afeiçoam-se a realidade do turismo, percebendo-se a evolução da prática dessa atividade em meio natural, como ressaltado por Beni (2000, p.55):

Tem se observado nesses últimos anos um notável fenômeno: a necessidade de buscar novas alternativas no uso do tempo livre, como escalar, dormir ao relento, dar caminhadas, banhos de cachoeiras, descoberta de novos lugares e outras atividades consideravas saudáveis chamada turismo ecológico.

Com o crescente aumento da procura pela prática do turismo em áreas naturais, nota-se que, quando na falta de estrutura de apoio adequado para uso turístico, essas áreas sofrem impactos ambientais, tornando-as vulneráveis à presença humana, fazendo com que haja aumento da degradação do meio, destruição da fauna e flora, entre outros. Baseado nestes impactos causados por esse tipo de turismo julga-se de 
extrema necessidade a avaliação e a elaboração de um planejamento turístico baseado na sustentabilidade, cujo entendimento, de acordo com Ruschmann (2001, p.9) é de "uma atividade ligada ao meio turístico que busca promover condições favoráveis de modo a atender as necessidades dos visitantes e da comunidade local envolvida buscando também a diminuição dos impactos, já que os mesmos não podem ser evitados". Nessa linha de raciocínio, a mesma autora afirma que:

Mesmo sem a intervenção humana, o meio ambiente se altera, dificultando também a definição das bases para os estudos de impacto. Muitos efeitos do turismo sobre o meio ambiente resultam de processos ambientais, que ocorrem em locais alterados pelo homem (RUSCHMANN, 2001, p.35).

Com suas raízes fincadas na natureza, há uma crescente preocupação com o meio no qual o turismo em áreas naturais acontece, fazendo com que o os hábitos, por parte dos visitantes, em relação à conservação e preservação do meio sejam repensados. No Brasil, país rico em áreas naturais, esta preocupação não é diferente, já que se observa um crescente aumento por este tipo de atividade, e levanta-se a questão da necessidade do planejamento atrelado à sustentabilidade, incluindo-se aí a segmentação do Ecoturismo.

De acordo com o Brasil (2006), o Ecoturismo é definido como um segmento da atividade turística que utiliza, de forma sustentável, o patrimônio natural e cultural, incentiva sua conservação e busca a formação de uma consciência ambientalista através da interpretação do ambiente, promovendo o bem-estar das populações envolvidas. Nessa perspectiva, nota-se que o Ecoturismo visa o desenvolvimento da educação ambiental, fator este observado também por Beni (2000, p.55) ao afirmar que o Ecoturismo é uma "atividade que tem de estar indissoluvelmente ligada ao trabalho de educação ambiental".

Mesmo o Ecoturismo sendo uma atividade ligada à educação ambiental, ainda há uma necessidade de sensibilização dos turistas a respeito da conservação (ambiental e social), buscando manter o meio visitado em boas condições para que este possa atender as necessidades de outros visitantes.

Sendo assim, compreende-se que a prática do Ecoturismo difere-se em relação a outras possibilidades do turismo por tratar-se de uso de recursos com alto risco de degradação pela presença humana. Nesse sentido, não apenas o destino ou atrativo tido como opção para a prática do Ecoturismo devem ser planejados para que se evite tal situação. É de grande importância trabalhar, principalmente, 0 turista que busca localidades com baixo grau de urbanização para realização e prática do turismo, no sentido de sensibilizá-lo, fazendo com que suas ações e relação com esse meio aconteçam da maneira mais equilibrada possível. 


\section{Especificidades do Ecoturismo}

Desenvolver o Ecoturismo significa, acima de tudo, oportunizar a criação de infraestrutura de apoio turístico para salvaguardar o patrimônio natural envolvido na concepção de um produto com essa caracterização. Existem situações, por exemplo, onde se tem a presença de espécies, sejam elas de fauna ou flora, endêmicas, ou seja, sem registro de aparição em outras localidades do globo e, por esse motivo, uma justificativa extremamente plausível acerca da proteção.

Tratando especificamente dos bens naturais, destaca-se que estes, em sua grande maioria, por localizarem-se em áreas extensas, têm o controle como um grande desafio, visto que a natureza vem sendo o foco do turismo, principalmente no Brasil, devido a sua biodiversidade.

Outro ponto muito importante e que não pode ser esquecido, é a presença da sinalização nas localidades onde 0 Ecoturismo é implementado, como forma de interagir com o turista, servindo ainda de ferramenta complementar a sensibilização na conduta enquanto em visita ao meio natural. A sinalização turística, de acordo com Fiori (2010) pode se apresentar em três formas: placas de identificação, placas de orientação e placas de interpretação, as quais promovem a comunicação visual entre turista e atrativo.

Em relação às áreas naturais utilizadas pelo Ecoturismo, a classificação das mesmas se dá em conformidade a sua extensão territorial e procedimentos administrativos, citando como exemplos (DOUROJEANNI; PAIVA, 2001):

a)RPPN - Reserva Particular do Patrimônio Natural - constituída por áreas privadas, geralmente vinculadas a empresas que possuem, dentre suas atividades, a exploração florestal, como é o caso de empresas produtoras de papel e celulose. Nesses casos, geralmente conta com espaços como trilhas, insetários e museu natural, permitindo a visita e a realização de atividades relacionadas à educação ambiental e turismo.

b)APA - Área de Proteção Ambiental: uma área em geral extensa, com certo grau de ocupação humana, dotada de atributos abióticos, bióticos, estéticos ou culturais especialmente importantes para a qualidade de vida e o bem-estar das populações humanas e tem como objetivos básicos proteger a diversidade biológica, disciplinar o processo de ocupação e assegurar a sustentabilidade do uso dos recursos naturais;

c)FLONA - Florestas Nacionais - estabelecidas com objetivos de promover o uso múltiplo sustentável dos recursos naturais, garantir a proteção dos recursos hídricos, das belezas cênicas e dos sítios históricos e arqueológicos, assim como fomentar o desenvolvimento da pesquisa científica básica e aplicada, da educação ambiental e das atividades de recreação, lazer e turismo;

d)Parques Estaduais: criados com a finalidade de preservar a fauna e flora nativa, principalmente as espécies ameaçadas de extinção, os recursos hídricos (nascentes, rios, cachoeiras) e formações geológicas. Nas áreas com baixo grau de degradação utiliza-se do turismo como ferramenta de conservação dos valores culturais, históricos e arqueológicos por meio de atividades relacionadas à educação ambiental. 
e)Parques Nacionais: tem como objetivo básico a preservação de ecossistemas naturais de grande relevância ecológica e beleza cênica, possibilitando a realização de pesquisas científicas e o desenvolvimento de atividades de educação e interpretação ambiental, de recreação em contato com a natureza e de atividades relacionadas ao turismo em áreas naturais.

Quanto ao público que busca o Ecoturismo, como forma de consumo, espera-se que este possua consciência de ações e atos para com o meio visitado. Mas esta não é uma situação que deve gerar o conformismo, pois, tratando-se de um país que sofre com o vandalismo de bens públicos, inclusive aqueles dotados com sistema de segurança, espera-se qualquer tipo de ação e comportamento.

Pressupõe-se que o ecoturista busca um ecossistema intacto, onde a fauna e flora desenvolveram-se em harmonia. Para Soifer (2005, p.19):

O ecoturista tem um bom padrão de vida. Ele não vem à procura de conforto, nem dos hábitos alimentares de seu país. Ao contrário, ele quer experimentar o típico local. Ele quer fazer esforço físico, ver, sentir, cheirar e, se possível, tocar e comer o inusitado, o único.

Espera-se do ecoturista, portanto, alguém bem informado, que antes de buscar determinado destino, realiza pesquisas em diferentes meios, como jornais, revistas, internet e agências especializadas a respeito do destino escolhido e espera da pessoa que o acompanha durante o passeio, respostas para suas mais variadas perguntas, como observa Soifer (2005, p.19): "o ecoturista espera muito do guia e do pessoal que o atende. Ele até pode aceitar que estes não tenham respostas para tudo, mas espera que a procurem para ele. Ele almeja um tratamento personalizado; para isto ele paga mais do que a média em viagens em grupo".

Como há uma cobrança maior dos colaboradores para esse tipo de turismo, estes têm sempre que estar atualizados, buscando o máximo de informações relacionadas a geologia, zoologia e botânica, devendo responder as perguntas sempre com clareza, verificando se esta é correta ou não, pois o turista designado a este tipo de atividade não aceita qualquer resposta para seus questionamentos. Na tentativa de dimensionar as características inerentes ao ecoturista, Soifer (2005, p.22) afirma que esse consumidor:

Possui muito contato com a natureza; é uma pessoa simples, transparente harmônica e saudável; raramente fuma ou bebe demais; não gosta de música alta nem de barulho; diz o que pensa, sem muito rodeio; Preza por uma alimentação saudável, sem fritura; em geral come carne branca; come muitos vegetais e frutas, de preferência crus; alguns são sensíveis ao excesso de sal, alho e pimenta; Gosta de acordar cedo e aproveitar a luz do dia; geralmente leva roupas para diferentes desafios. 
Muitas são as características apresentadas por esse tipo de turista, o que requer muito cuidado nos produtos e serviços oferecidos para o mesmo, pois cada turista interessado na natureza possui um foco diferente que influencia em suas expectativas e seu comportamento. Vale ressaltar também que o ecoturista como qualquer outro turista, preza muito por sua segurança, o que faz com que o pessoal responsável por esse tipo de serviço trabalhe bastante tal aspecto, passando para o visitante segurança, desde o momento de sua chegada até sua partida. Diante desses diferentes focos e interesses, destacam-se alguns dos nichos em Ecoturismo, observados por Soifer (2005, p.25):

Ornitólogos: são aqueles que estudam os pássaros, geralmente formados por estudantes ligados a universidades, pintores, profissionais e professores de botânica e zoologia; Montanhistas: sobem montanhas basicamente com os pés e não com as mãos. Ou seja, os que, mesmo levando cordas usando botas especiais, apenas em raras exceções usam grampos na rocha. Sua meta principal é atingir cumes de onde desfrutam de uma bela vista. Este lazer/esporte exige ótima condição física, treino, algum equipamento e um guia muito competente; Orquidólogos, botânicos e apreciadores de flores naturais: são aqueles que apreciam e/ou estudam as flores em seu habitat. Há flores que atraem turistas por seu perfume mais do que por sua beleza (ex: dama da noite).

Além destes, existem variados nichos apresentados no Ecoturismo, entretanto, faz-se necessário o cuidado pela qualidade desses serviços oferecidos, pois grande parte deles possui riscos e exigem diversos equipamentos de segurança, elevando o custo da atividade, no entanto, o turista que sai de sua casa para realizar tal atividade prima sempre por sua qualidade e o grau de satisfação oferecido, não se importando com o valor a ser pago, já que a busca pela satisfação de suas expectativas é o motivo principal da viagem ou deslocamento.

\section{O Parque Nacional de Sete Cidades (PN7C): estrutura e potencial para o turismo}

Localizado na porção meio-norte do estado do Piauí e distante cerca de 200 quilômetros da capital, Teresina, o Parque Nacional de Sete Cidades (PN7C) é portador de uma área correspondente a 6.221ha., cujo território distribui-se entre os municípios de Brasileira, Piracuruca e Piripiri, com perímetro aproximado de 36 quilômetros e relevo suave ondulado.

O clima da região é o semiárido, com seis meses secos, com pluviosidade média anual entre 1000 a 1250 mm, numa região classificada como zona equatorial tropical, com temperatura média anual variando entre $24^{\circ} \mathrm{C}$ a $26^{\circ} \mathrm{C}$, tendo uma temperatura máxima absoluta entre $38^{\circ} \mathrm{C}$ a $40^{\circ} \mathrm{C}$ e mínima absoluta $12^{\circ} \mathrm{C}$ a $16^{\circ} \mathrm{C}$ (IBAMA, 2011).

O PN7C abriga a flora e fauna de dois ecossistemas que entrecortam o parque: Cerrado e Caatinga. Criado em 08 de junho de 1961, através do 
decreto 50.744, é administrado pelo Instituto Chico Mendes de Conservação da Biodiversidade - ICMBio. A área de visitação do parque corresponde a 9\% (ou 490 ha.) de sua extensão (MOREIRA; MAVIGNIER, 2007).

Em relação a sua fauna, verifica-se a ocorrência da suçuarana (Felis concolor), gato-do-mato (Leopardus tigrinus); cachorro-do-mato (Cerdocyon thous), paca (Agouti paca), mocó (Kerodon rupestris), camaleão (Chamaeleo chamaeleon) e as serpentes peçonhentas, como jararaca (Bothrops jararaca) e cascavel (Crotalus durissus terrificus). A sua flora possui plantas importantes como fontes alimentares para a fauna selvagem, tais como a mangabeira (Hancornia speciosa) a guabiroba (Campomanesia xanthocarpa), o pequizeiro (Caryocar brasiliense) e o bacurizeiro (Platonia insignis). Do ponto de vista florístico, ocorrem na área, entre outras, as juremas (Mimosa tenuiflora), o xiquexique (Pilosocereus gounelleı) e ipê amarelo (Tabebuia serratifolia) (IBAMA, 2011).

Sua composição geológica, de acordo com Fortes (1996) é composta por uma área de sedimentação antiga da região do Meio Norte do Brasil, com camadas horizontais ou quase horizontais de rochas arenosas, principalmente arenitos avermelhados de origem continental.

As diversas histórias e lendas relacionadas às "Sete Cidades de Pedra", tornam-se colaborativas à experiência turística vivenciada no local. Muitos são os comentários a respeito do parque, tecidos por historiadores, pesquisadores e turistas, diante do que viram e/ou ouviram. Outras suposições e lendas também foram criadas por antigos, estudiosos e pesquisadores, que dizem que Sete Cidades foi também local de passagens dos fenícios, centro intelectual dos povos tupis, antigo golfo marítimo visitado pelos navegadores vikings, cidade encantada, entre outras que fazem de Sete Cidades um local cheio de mistérios. (MOREIRA; MAVIGNIER, 2007).

Sendo um dos principais pontos turísticos e de pesquisas científicas da região nordeste brasileira, principalmente nas áreas de arqueologia, geologia e botânica, o PN7C é integrante do roteiro turístico Serras Nordeste, desenvolvido pelo Governo dos Estados do Piauí e Ceará em parceria com o Serviço Nacional de Apoio a Pequena e Média Empresa (SEBRAE) de ambos estados, envolvendo no estado do Piauí os municípios de Piripiri, Piracuruca e Pedro II e, no estado do Ceara o Parque Nacional de Ubajara, localizado em município de mesmo nome, bem como as cidades de Tianguá e Viçosa, no modelo de consórcio turístico regional. De acordo com entrevista concedida pelo presidente do conselho deliberativo do Sebrae Piauí ${ }^{1}$ :

O Serras Nordeste segue o exemplo da Rota das Emoções, primeiro consórcio turístico do país e que tem conquistado surpreendentes resultados em geração de trabalho e renda. O Serras Nordeste tem outros apelos turísticos que são o clima ameno, as belezas naturais dessas regiões, além da extração da opala em Pedro II. O roteiro pretende estimular o surgimento de novos negócios entre Sete Cidades e a Serra da Ibiapaba, como também melhorar o desempenho dos pequenos negócios já existentes. 
De sua estrutura para o turismo, fazem parte trilhas, mirante, espaço para camping e pousada. Na conjuntura do turismo em áreas naturais, 0 PN7C proporciona atividades contemplativas e interativas à natureza com potencial para a prática do cicloturismo, trekking, banhos e birdwatching e, na perspectiva do turismo contemporâneo, em consideração a variedade geológica do PN7C, apresenta potencial para o geoturismo que, de acordo com Moreira (2008, p.69) é:

Uma segmentação turística sustentável, realizada por pessoas que têm o interesse em conhecer mais os aspectos geológicos e geomorfológicos de um determinado local, sendo esta a sua principal motivação na viagem. Mas, apesar de ser um novo segmento, não chega a ser um modismo, pois se fosse um termo passageiro, não integraria diversos documentos oficiais da UNESCO e não estaria sendo tão comentado e pesquisado a nível mundial.

Suas várias formações rochosas, datadas de cerca de 190 milhões de anos, possuem diversos nomes, tamanhos e formas. Lembram mapas, animais, objetos, entre outros, que variam de acordo com a imaginação do visitante, além de possuir banhos de riachos e piscinas naturais, como também uma cachoeira com volume de água perene (seca fora do período chuvoso). Encontra-se ainda no parque uma variedade de inscrições rupestres, sendo a pintura da mão de seis dedos a mais famosa, seguida da pintura do lagarto. Além dos banhos, cachoeira e formações rochosas, o parque encontra-se dividido em sete cidades, dispostas da seguinte forma:

- Primeira Cidade - Composta pela Piscina dos Milagres (nascente que nunca deixou de jorrar, mesmos nos períodos mais difíceis da seca); Pedra dos Canhões: Pedra da Gia; Salão do Pajé (com inscrições rupestres);

- Segunda Cidade - Composta pelo Arco do Triunfo (um dos atrativos mais fotografados de sete cidades, batizado por lembrar o arco francês); Pedra do Americano (em 1951, quatro americanos armaram barraca e mandaram que os moradores cavassem a base de uma rocha, orientados por algumas inscrições em formatos de seta); Vista Panorâmica (com 82 metros de altura, é o ponto mais alto do parque, ofertando uma visão panorâmica de grande parte do parque); Biblioteca (atrativo que lembra um local de leitura, com livros e papéis empilhados); Pé do Gigante (um pé esquerdo marcado na rocha, com o detalhe de seus cinco dedos);

- Terceira Cidade - Composta por Cabeça de Dom Pedro I (nome recebido pela aparência do perfil do rosto do Imperador do Brasil); Pedra do beijo (duas rochas encostadas rosto a rosto como se beijassem); Dedo de Deus (menir lembrando o formato de um dedo); Pedra do Pombo (lembra um pombo pousando sobre uma rocha).

- Quarta Cidade - Composta pela Gruta do Catirina (gruta onde morou José Catirina, um famoso curandeiro da região do início do século 
XX); Archete (passagem que leva a outros atrativos); Mapas do Brasil e Ceará (formados por uma abertura na rocha, de um lado assemelha-se ao mapa do Brasil, de outro o do Ceará); Cabeça de Águia; Pedra dos dois Lagartos, Pedra dos Dois Irmãos; Leão Deitado.

- Quinta Cidade - Composta pela Pedra do Camelo (lembra a forma de um camelo dromedário, de apenas uma corcova); Furna do Índio (contém inscrições rupestres que lembram rituais de caça); Pedra do Rei (lembra um rei de costas, com seu manto e coroa); Casa do Guarda (lembra um guarda de prontidão numa cabana, como se vigiasse a cidade); Pedra das Inscrições (contém pinturas préhistóricas);

- Sexta Cidade - Composta pela Pedra da Tartaruga (assemelha-se o casco de uma tartaruga pelo processo de craquelagem da rocha em decorrência da ação do tempo); Pedra do Elefante (forma de um elefante com a tromba em destaque); Pedra do Cachorro (rocha com o formato do rosto de um cachorro);

- Sétima Cidade - é uma reserva Ecológica para preservação da fauna, flora e dos monumentos ricos em inscrições pré-históricas. $O$ acesso somente é permitido com autorização do IBAMA.

A Figura 1 demonstra alguns dos atrativos e formações rochosas existentes no PN7C.

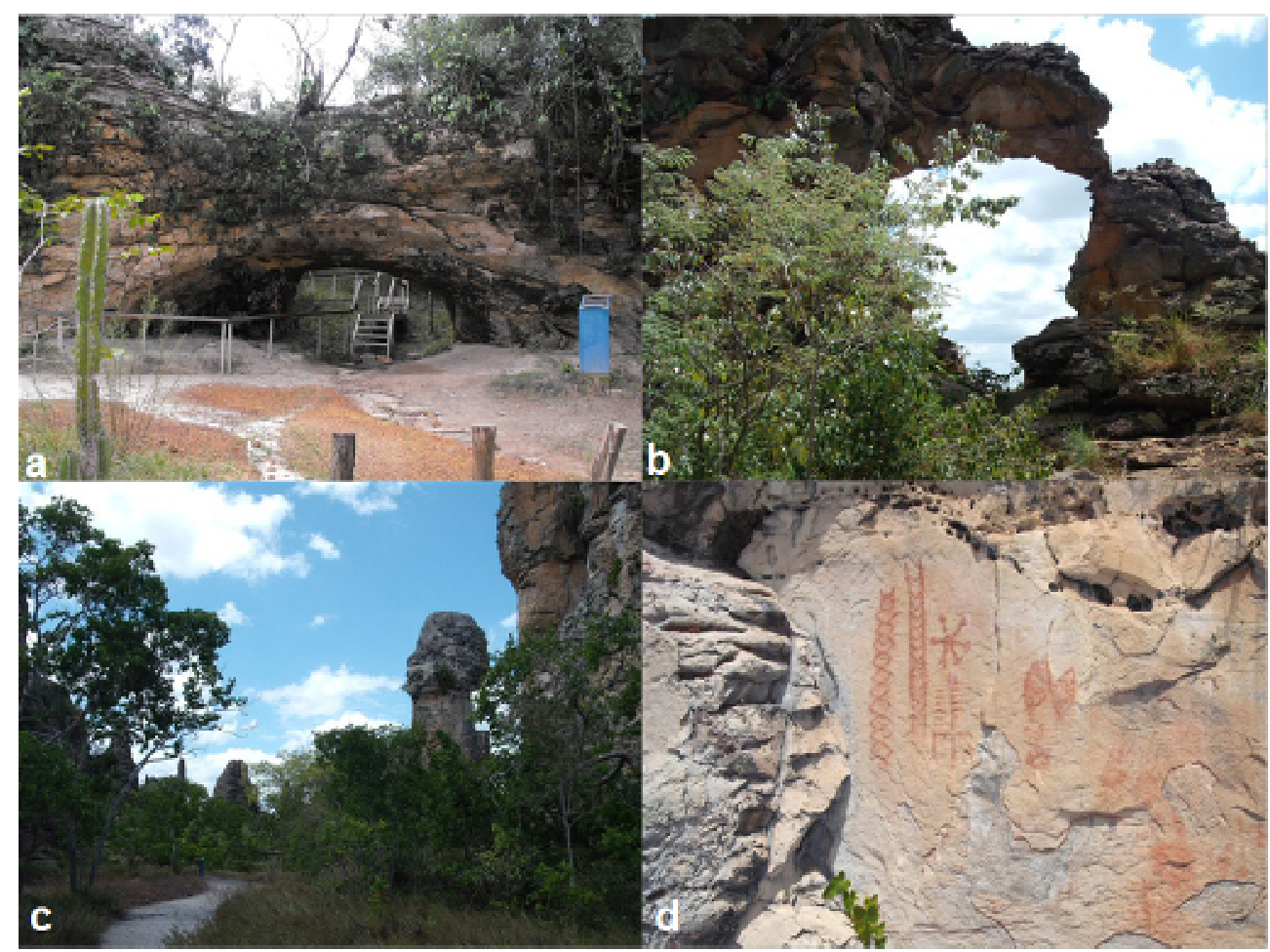

Figura 1: alguns dos atrativos / formações rochosas encontrados no PN7C (a. archete;

b. mapa do Ceará; c. Cabeça de Dom Pedro; d. inscrições rupestres)

Figure 1: Some of the attractions / rock formations found in PN7C (a. archete; b map of Ceará; c. head of Dom Pedro; d. inscriptions) 
A manutenção do parque é terceirizada, por empresas contratadas por licitação, cuja limpeza e aparo do mato nas proximidades das trilhas são feitos a cada três meses, de acordo com a necessidade do local; no entanto, a associação de condutores busca desenvolver um projeto que envolva funcionários e visitantes na responsabilidade de se manter o local limpo e organizado, de modo a proporcionar uma reorientação de verba para outras necessidades observadas, tais como a manutenção das placas interpretativas, cuja importância é destacada por Moreira (2008, p.70):

Muitos turistas que não possuem conhecimentos sobre a geologia veem esses aspectos como um componente curioso e interessante da paisagem, sendo que no geoturismo se entende que não há somente a apreciação da paisagem, e sim também sua compreensão, realizada com o auxílio dos meios interpretativos.

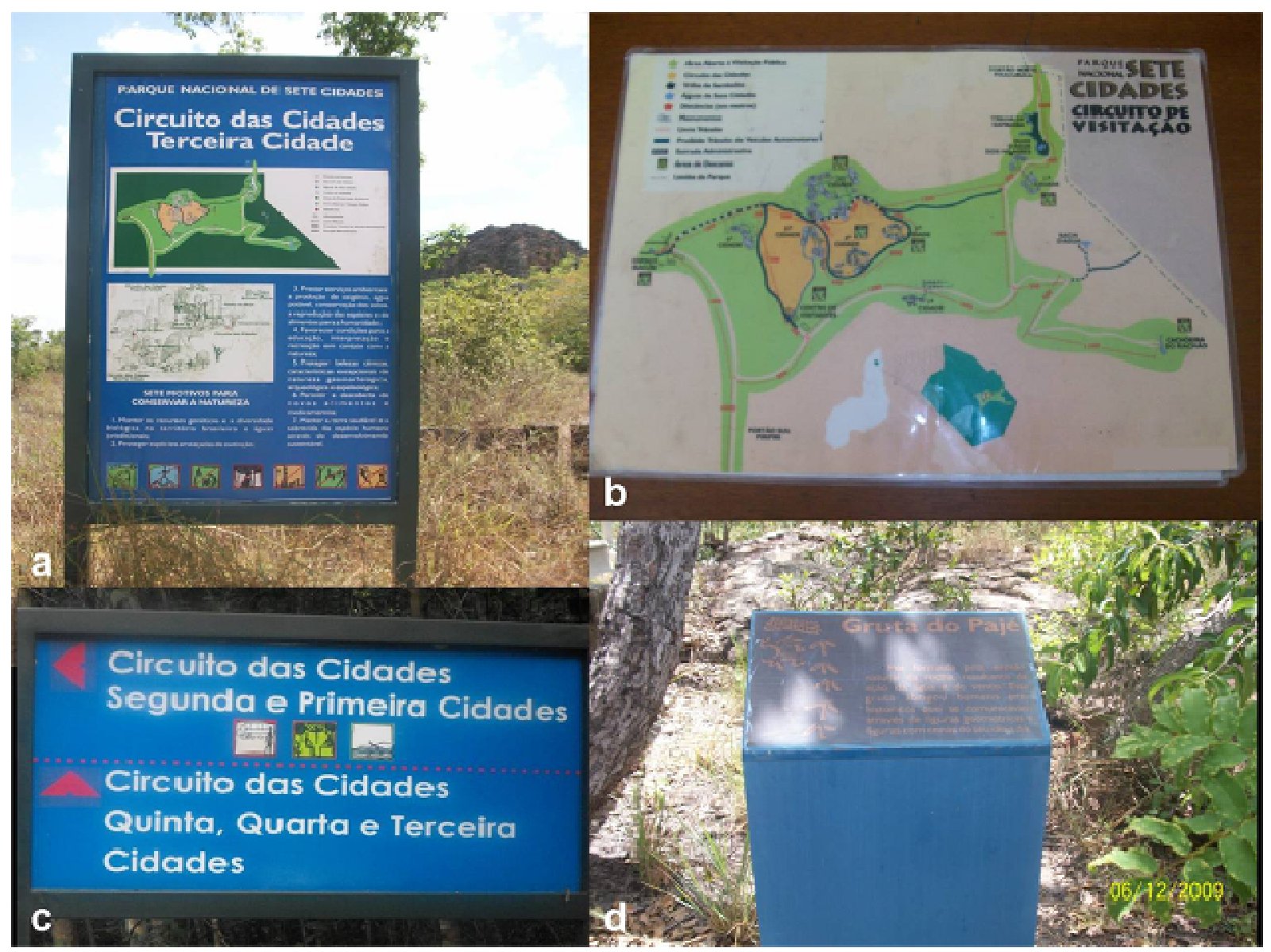

Figura 2: placas interpretativas observadas no PN7C (a. modelo de sinalização utilizado em cada uma das cidades; b. mapa da área total disponível para visitação; c. detalhe de comunicação visual com pictogramas indicando atividades passíveis de execução no PN7C; d. placa degradada pela ação do tempo).

Figure 2:. Interpretive plaques observed in PN7C (a. signaling model used in each of the cities; b. map of the total area available for visitation; c. detail of visual communication activities with pictograms indicating enforceable in PN7C; $d$. plate degraded by weather). 
O PN7C dispõe de 370 placas interpretativas, reformadas em 2008 e distribuídas por toda a área liberada para visitação. Algumas, em decorrência da ação do tempo encontram-se em mau estado de conservação, mas a maioria proporciona ao turista a interpretação do patrimônio natural e geológico visitado (Figura 2).

\section{Diagnóstico do PN7C: caracterização e conduta do público visitante do e degradações observadas no patrimônio natural e geológico}

Para se traçar o diagnóstico da caracterização do público visitante do PN7C e sua conduta enquanto ecoturista, três visitas foram realizadas ao local, entre os anos de 2009 a 2011, utilizando do método de observação participante que, de acordo com Atkinson e Hammersley (1994) é aquela onde o pesquisador desempenha um papel participante estabelecido na cena estudada.

Além desta, utilizou-se de entrevista com base em questionários semiestruturados junto aos condutores do parque, abordando aspectos relacionados à conduta e procedimentos adotados pelos funcionários do PN7C durante a visita, além de busca de informações, em caráter empírico, que dizem respeito à composição da demanda de turistas e excursionistas, com acesso aos livros de registro de visita, bem como o registro fotográfico de diferentes partes do PN7C como forma de ilustrar a presente pesquisa.

De acordo com as informações obtidas durante a pesquisa, o processo de visitação no PN7C se inicia pelo direcionamento do turista ou grupo de turistas ao centro de visitantes, localizada a cinco quilômetros da guarita de entrada do parque. A forma mais usual de deslocamento na área permitida para visita se dá em carro de passeio (de propriedade do visitante), em decorrência da distância entre as cidades, existindo também a possibilidade de ser feito a pé, ônibus ou bicicleta. Os visitantes são recepcionados em uma estrutura que conta com um anfiteatro com capacidade para aproximadamente 40 pessoas, banheiro e salão de recepção com exposição de souvenires para venda como artesanatos, camisetas e livros.

O deslocamento pelo parque, a partir do centro de visitantes, se dá, obrigatoriamente, com a presença de um condutor, registrado na Associação de Condutores de Visitantes em Ecoturismo do Meio Norte do Piauí, composta por 20 guias regulamentados, todos moradores da região em que se encontra o PN7C (Piripiri, Piracuruca e Brasileira), os quais participaram de treinamentos que visam atender as especificidades de qualidade no atendimento ao turista e procedimentos de segurança, em conformidade aos padrões do SNUC 2003/1996. As opções de roteiro são previamente estabelecidas de acordo com interesse e disponibilidade do visitante, cuja duração varia de uma a até três horas e meia de passeio. Cada condutor é orientado a acompanhar um grupo de, no máximo, dez pessoas.

A comunicação entre a central de apoio e os condutores é feita por rádio, que, no momento da última visita para a realização da presente pesquisa (maio de 2011) encontrava-se desativado devido à reforma pela 
qual está passando a central de apoio. O condutor que acompanhou os pesquisadores na visita realizada em 2009 declarou ter experiência superior a sete anos na função de acompanhamento de visitantes, demonstrando conhecimento avançado sobre aspectos históricos, geológicos e geográficos do parque, afirmando que as informações por ele repassadas (de caráter biológico e geológico) são parte integrante do treinamento realizado com os membros da Associação de Condutores vinculada ao PN7C.

A demanda de visitantes é diversa, composta, além de ecoturistas e turistas de lazer, por pessoas com interesse pedagógico (professores e alunos do ensino fundamental e médio), científico (antropólogos, biólogos, geólogos) e grupos distintos como ufólogos e praticantes de loga por interpretarem o local como um campo energético. A visitação média do PN7C é de 40 mil pessoas/ano, composta por residentes do estado do Piauí (40\%), estados vizinhos como Maranhão e Ceará (30\%), turistas estrangeiros $(20 \%)$ e turistas procedentes de outros estados brasileiros $(10 \%)$, sendo mais frequente o fluxo de pessoas nos finais de semana e durante as férias escolares. Destaca-se, contudo, a inexistência de um estudo de capacidade de carga no local.

As visitas de caráter pedagógico (configuradas em excursões) concentram-se, na maioria dos casos, nos finais de semana. A pré-agenda de visitação não é obrigatória, ainda assim algumas excursões ligam para o parque agendando a visita, entretanto, quando não há o pré agendamento por parte dos excursionistas nota-se, eventualmente, uma falta de condutores, fazendo com que os visitantes esperem a disponibilidade de um condutor para a realização do passeio.

Quando há um grupo de visitantes com criança ou idoso, a visita geralmente, é de caráter observatório, de dento dos respectivos automóveis, caracterizando um roteiro rápido e pouco cansativo. Existem casos, contudo, com a presença desse tipo de visitante (idosos ou crianças) o interesse pela interação com o espaço natural, ou seja descendo do veículo para um maior contato com a natureza e um maior entendimento a respeito do parque.

Analisando a conservação do Parque, este se encontra, em aspectos gerais, numa boa condição, salvo os casos de desgaste de algumas das rochas devido à ação do vento, sol e chuva, acontecendo o mesmo com algumas das placas informativas. Mas a ação antrópica demonstra ser a principal responsável pela degradação observada em alguns pontos do parque. Por esse motivo, os condutores buscam proteger a formação original do parque, evitando que os visitantes toquem e/ou subam nas rochas, "construindo" trilhas específicas, a fim de conservar e manter o bom estado das mesmas. Em relação às trilhas no arenito (principal rocha que compõe a estrutura geológica do parque), Melo; Bosetti; Godoy e Pilatti (2002, p.276) destacam que "além dos fatores naturais que promovem a erosão dos arenitos, destaca-se também a erosão das trilhas pelo pisoteio dos visitantes e importante depredação por inscrições".

Nesse sentido, Maganhotto (2006, p.49) defende que "as trilhas devem transmitir informações concisas e objetivas de uma forma harmônica com a natureza, para isto estas devem ser planejadas e os materiais 
utilizados na sua estruturação devem ser simples e compatíveis com o meio natural, evitando determinadas agressões visuais no local'. Outro aspecto observado foi a inscrição em rochas, pela ação antrópica, possivelmente ocasionada pela dificuldade de controle de pessoas que visitam o local, haja vista a distância entre a guarita do parque e o centro de visitantes, permitindo o acesso a algumas das cidades sem a presença de um condutor. Além da ação antrópica, cita-se também a dificuldade na manutenção de algumas pinturas rupestres, seja pela ação do tempo ou de insetos que fazem ninhos e caminhos em cima das pinturas, prejudicando não apenas sua visibilidade, mas colocando em risco sua conservação, haja vista sua importância histórica e antropológica. Tais situações podem ser observadas na Figura 3.

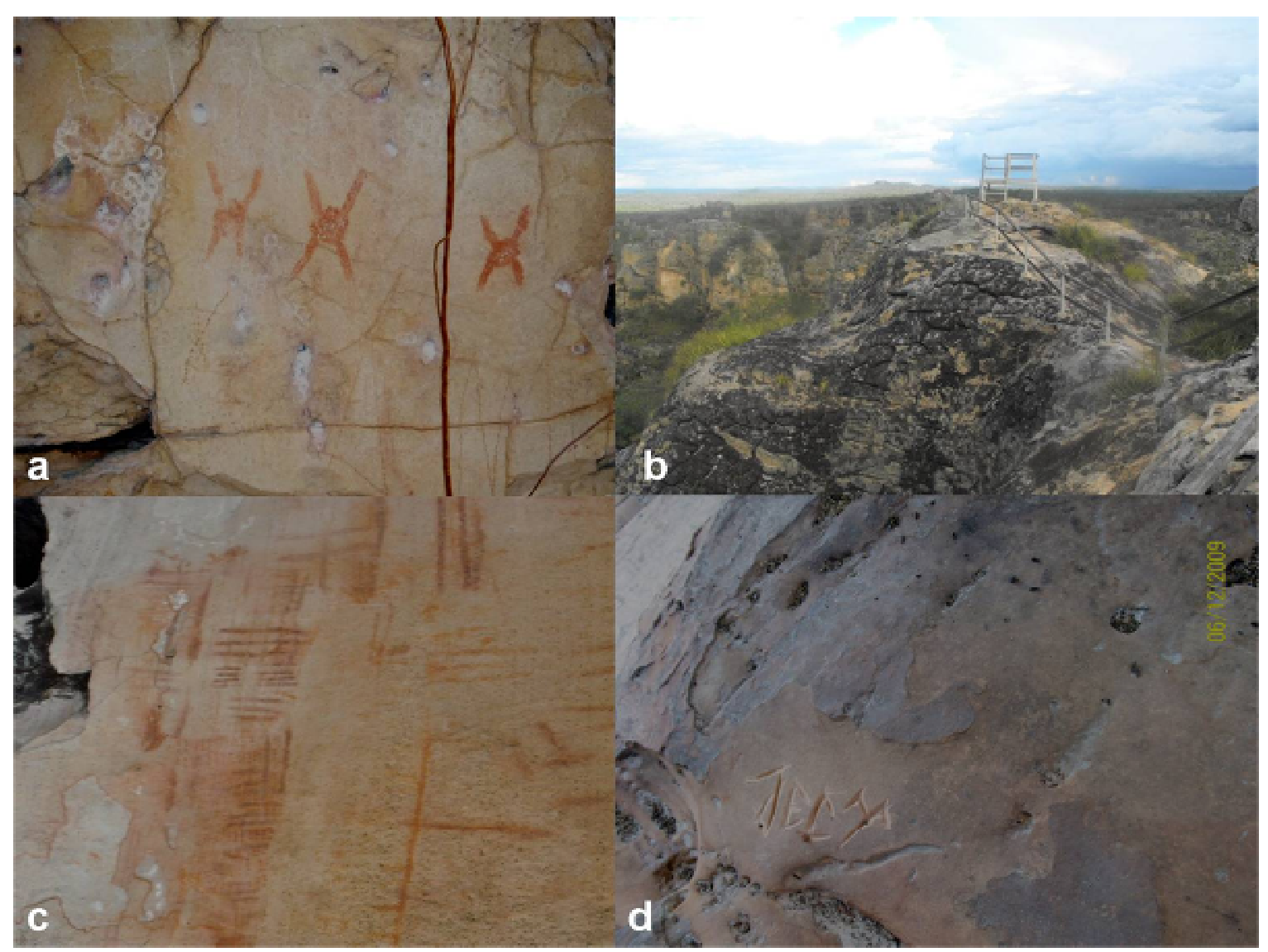

Figura 3: diferentes formas de degradação ao patrimônio natural do PN7C (a. inscrições rupestres com degradação pela ação antrópica [a esquerda das pinturas rupestres] e ação de insetos; b. trilha sem proteção para a rocha; c. inscrições rupestres com degradação pela ação do tempo [canto inferior esquerdo]; d. ação antrópica na rocha)

Figure 3: Different forms of degradation to the natural heritage of PN7C (a. inscriptions to degradation by human action [the left of the cave paintings] and insect action b unprotected trail to the rock $c$ inscriptions with the degradation.. action time [lower left];. d human action on the rock) 


\section{Considerações finais}

No ensejo de se buscar uma melhor relação entre turista e atrativo no PN7C, a primeira providência é a efetivação no estudo de sua capacidade de carga, como forma de orientação às ações futuras que venham acontecer no local, por meio de um plano de desenvolvimento do turismo que deverá atender a proteção do patrimônio natural e geológico, o envolvimento da comunidade residente no entorno do parque e o fluxo de visitantes do local, bem como contemplar a prática da sustentabilidade em seus aspectos ambientais, socioculturais e econômicos.

O anfiteatro existente no centro de visitantes, hoje subutilizado, deve ser palco de atividades de educação ambiental, como elemento colaborativo a conduta dos visitantes em conformidade ao turismo sustentável, especialmente para grupos com crianças, buscando a construção de uma sociedade ambientalmente responsável, por meio de explicações inerentes à proibição de determinadas ações, como a subida em pedras e 0 arrancar de plantas, ilustradas pela necessidade da natureza em manter sua fauna e flora equilibradas.

A estrutura do parque, mesmo apresentando boas condições, no geral, carece de ações como a proteção das pinturas rupestres, manutenção das placas interpretativas danificadas pela ação do tempo, manejo das trilhas, especialmente aquelas que se localizam na superfície do terreno com formação de arenito a fim de evitar seu desgaste. Outra situação negativa observada é o acesso sem o acompanhamento dos condutores a algumas das cidades.

Sobre o manejo, nota-se a possibilidade de adaptação de algumas das trilhas para acesso de cadeirantes, proporcionando a execução de atividades e projetos direcionados a pessoas com necessidades especiais, portanto praticando a inclusão social. Já o deslocamento indevido a algumas das cidades pode ser evitado por meio de um monitoramento mais rigoroso, seja pela comunicação de rádio sempre que novos visitantes adentram ao parque, ou pelo posicionamento de colaboradores no trajeto de cinco quilômetros que separam a guarita de entrada e o centro de visitantes.

A participação do PN7C no roteiro integrado Serras Nordeste demonstra possibilidade no incremento da demanda, aproveitando o fluxo de turistas que se dirigem ao estado do Ceará, podendo proporcionar novas oportunidades de emprego e renda, tanto para a formação de novos condutores como para o fortalecimento do trade da região. Paralelamente, sugere-se o incentivo na oferta de cursos de qualificação profissional, em especial idiomas, já que, da demanda que visita o parque, $20 \%$ é composta por estrangeiros, justificando ainda a disposição de informações nas placas não somente em português, mas também inglês e espanhol para que sua função interpretativa também seja feita pelos estrangeiros.

Boullón (2002) ao descrever a zonificação do espaço turístico, trata, dentre outros, da existência dos centros de escala, cuja influência de atração de visitantes encontra-se inserida num raio de até $200 \mathrm{~km}$. Como a capital do estado é a única cidade que conta com serviço regular de aviação comercial, é considerada o principal portão de entrada àqueles que chegam ao Piauí por via aérea, subentendendo que turistas hospedados em 
Teresina possam usufruir da visita ao parque em viagem de ida-e-volta no mesmo dia, fazendo do PN7C um elemento agregador de valor a experiência turística daqueles que visitam a capital e também por moradores do estado que, ao deslocarem-se entre a capital e o litoral do Piauí, especialmente nos feriados e recesso escolar, sequer consideram a possibilidade de uma visita ao local.

Tal condição justifica a importância na promoção turística do PN7C de forma exaustiva junto aos moradores do estado, como forma de incentivo a visitação, por meio de distribuição de materiais como folhetos informativos e mapas a se distribuir no comércio dos municípios inseridos no raio de influência do parque.

Por fim, a promoção do Parque como destino turístico no Piauí para a prática de Ecoturismo e demais segmentações do turismo em áreas naturais, como safári fotográfico, birdwatching, trekking, cicloturismo, corridas de orientação e o geoturismo pela sua relevância à pratica da sustentabilidade, já que este, de acordo com Moreira (2008) deve ser uma modalidade de turismo que permita seu desenvolvimento sem degradar ou esgotar os recursos, portanto, em conformidade aos princípios do turismo sustentável.

\section{Referências Bibliográficas}

ATKINSON, P.; HAMMERSLEY, M. Ethnography and participant observation. Londres: Sage, 1994.

BENI, M.C. Análise Estrutural do Turismo. 3. ed. São Paulo, SENAC, 2000.

BOULLÓN, R. Planejamento do espaço turístico. Bauru: EDUSC, 2002.

BRASIL. Ministério do Turismo. Secretaria Nacional de Políticas de Turismo. Segmentação do Turismo: marcos conceituais / Ministério do Turismo, Coordenação geral de segmentação. Brasília: Ministério do Turismo, 2006

DOUROJEANNI, M.J.; PAIVA, M.T.J. Biodiversidade: a hora decisiva Curitiba: Editora da Universidade Federal do Paraná, 2001.

FIORI, S.R. Os símbolos de informação pública nos setores do lazer e turismo: resultados empíricos. Turismo em análise $v 21, \mathrm{n} 2$, p. $381-405$, 2010.

FORTES, F.P. Geologia de Sete Cidades. Teresina: Fundação Monsenhor Chaves, 1996.

IBAMA. Instituto Brasileiro do Meio Ambiente e dos recursos Hídricos. Parque Nacional de Sete Cidades. Disponível em $<$ http://www.ibama.gov.br/revista/7cida/texto 7cida.htm>, acesso em 08/12/2011.

MELO, M.S.; BOSETTI, E.P.; GODOY, L.C.; PILATTI, F. Vila Velha (PR): impressionante relevo ruiniforme. In: SCHOBBENHAUS, C.; CAMPOS, D.A.; QUEIROZ, E.T.; WINGE, M.; BORN, M.L.C. (ed.). Sítios geológicos e paleontológicos do Brasil 1. ed. Brasília: DNPM/CPRM, 2002. 
MAGANHOTTO, R.F. Fragilidade, impactos e prevenções das trilhas em áreas naturais protegidas: estudo de caso reserva ecológica Ytaytyba RPPN 2006, 137f. Dissertação (Mestrado em Geografia) Universidade Federal do Paraná, Curitiba, 2006.

MOREIRA, J.C. Patrimônio geológico em unidades de conservação: atividades interpretativas, educativas e geoturísticas, 2008, 468f. Tese (Doutorado em Geografia) Universidade Federal de Santa Catarina, Florianópolis, 2008.

MOREIRA, A.M.; MAVIGNIER, D.S. Conhecendo história e geografia do Piauí. Parnaíba: Gráfica Ferraz, 2007.

RUSCHMANN, D.V.M. Turismo Planejamento Sustentável: a proteção do meio ambiente. 7. ed. São Paulo: Papirus, 2001.

SOIFER, J. Empreender em Turismo e Ecoturismo. Rio de Janeiro: Qualitymark, 2005.

Nota:

${ }^{1}$ Disponível em <http://www.portalaz.com.br/noticia/geral/133799>, acesso em 09/12/2011.

Ricardo Gomes Ramos: Universidade Federal do Piauí, Teresina, PI, Brasil.

E-Mail: ricardo0219@hotmail.com

Link para o currículo Lattes: http://lattes.cnpq.br/3920356245716937

Luísa Cristina Paiva e Paixão: Universidade Federal do Piauí, Teresina, PI, Brasil.

E-Mail: luisacristina31@hotmail.com

Link para o currículo Lattes: http://lattes.cnpq.br/8863179062235471

Data de submissão: 27 de junho de 2012

Data de recebimento de correções: 14 de dezembro de 2012

Data do aceite: 14 de dezembro de 2012

Avaliado anonimamente 